University of Nebraska - Lincoln

DigitalCommons@University of Nebraska - Lincoln

NASA Publications

National Aeronautics and Space Administration

2002

\title{
MODIS Snow-Cover Products
}

Dorothy K. Hall

Hydrological Sciences Branch, NASA/Goddard Space Flight Center, Code 974, Greenbelt, MD

George A. Riggs

Science Systems and Applications, Inc., Lanham, MD 20706, USA

Vincent V. Salomonson

NASA/Goddard Space Flight Center, Code 900, Greenbelt, MD 20771, USA

Nicolo E. DiGirolamo

Science Systems and Applications, Inc., Lanham, MD 20706, USA

Klaus J. Bayr

Department of Geography, Keene State College, Keene, NH 03431, USA

Follow this and additional works at: https://digitalcommons.unl.edu/nasapub

Part of the Physical Sciences and Mathematics Commons

Hall, Dorothy K.; Riggs, George A.; Salomonson, Vincent V.; DiGirolamo, Nicolo E.; and Bayr, Klaus J., "MODIS Snow-Cover Products" (2002). NASA Publications. 1.

https://digitalcommons.unl.edu/nasapub/1

This Article is brought to you for free and open access by the National Aeronautics and Space Administration at DigitalCommons@University of Nebraska - Lincoln. It has been accepted for inclusion in NASA Publications by an authorized administrator of DigitalCommons@University of Nebraska - Lincoln. 


\title{
MODIS snow-cover products
}

\author{
Dorothy K. Hall ${ }^{\mathrm{a}, *}$, George A. Riggs ${ }^{\mathrm{b}}$, Vincent V. Salomonson ${ }^{\mathrm{c}}$, \\ Nicolo E. DiGirolamo ${ }^{\text {, Klaus J. Bayr }}{ }^{\mathrm{d}}$ \\ ${ }^{\mathrm{a}}$ Hydrological Sciences Branch, NASA/Goddard Space Flight Center, Code 974, Greenbelt, MD 20771, USA \\ ${ }^{\mathrm{b}}$ Science Systems and Applications, Inc., Lanham, MD 20706, USA \\ ${ }^{\mathrm{c}}$ NASA/Goddard Space Flight Center, Code 900, Greenbelt, MD 20771, USA \\ ${ }^{\mathrm{d}}$ Department of Geography, Keene State College, Keene, NH 03431, USA
}

Received 1 April 2001; received in revised form 20 December 2001; accepted 1 February 2002

\begin{abstract}
On December 18, 1999, the Terra satellite was launched with a complement of five instruments including the Moderate Resolution Imaging Spectroradiometer (MODIS). Many geophysical products are derived from MODIS data including global snow-cover products. MODIS snow and ice products have been available through the National Snow and Ice Data Center (NSIDC) Distributed Active Archive Center (DAAC) since September 13, 2000. MODIS snow-cover products represent potential improvement to or enhancement of the currently available operational products mainly because the MODIS products are global and 500-m resolution, and have the capability to separate most snow and clouds. The MODIS snow-mapping algorithms are automated, which means that a consistent data set may be generated for longterm climate studies that require snow-cover information. Extensive quality assurance (QA) information is stored with the products. The MODIS snow product suite begins with a 500-m resolution, 2330-km swath snow-cover map, which is then gridded to an integerized sinusoidal grid to produce daily and 8-day composite tile products. The sequence proceeds to a climate-modeling grid (CMG) product at $0.05^{\circ}$ resolution, with both daily and 8-day composite products. Each pixel of the daily CMG contains fraction of snow cover from $40 \%$ to $100 \%$. Measured errors of commission in the CMG are low, for example, on the continent of Australia in the spring, they vary from $0.02 \%$ to $0.10 \%$. Near-term enhancements include daily snow albedo and fractional snow cover. A case study from March 6, 2000, involving MODIS data and field and aircraft measurements, is presented to show some early validation work.
\end{abstract}

(C) 2002 Elsevier Science Inc. All rights reserved. This article is a U.S. government work, and is not subject to copyright in the United States.

\section{Introduction}

Snow-cover maps of the Northern Hemisphere have been available since 1966 from the National Oceanic and Atmospheric Administration (NOAA). These maps have continually been improved as new satellite data have become available. These maps, however, are not global and they rely on analysts to fine-tune the maps. For operational use, this is an advantage. However, for long-term climate studies, it is imperative to have a data set that is developed using an objective technique for snow mapping so that the data from the maps can be consistent when used as input to climate models.

On December 18, 1999, the Earth Observing System (EOS) Terra spacecraft was launched with a complement of five instruments, one of which is the Moderate Resolution Imaging Spectroradiometer (MODIS). MODIS data are now being used to produce snow-cover products from automated algorithms at Goddard Space Flight Center in Greenbelt, MD. The products are transferred to the National Snow and Ice Data Center (NSIDC) in Boulder, $\mathrm{CO}$, where they are archived and distributed via the EOS Data Gateway (EDG).

The MODIS snow-cover maps represent a potential improvement relative to hemispheric-scale snow maps that are available today mainly because of the improved spatial resolution and snow/cloud discrimination capabilities of MODIS, and the frequent global coverage. Their accuracy, however, has not yet been established, nor has the accuracy of existing operational maps. The difficulty in establishing the accuracy of any of these maps is that it is not known which map is the "truth" (if any) and the techniques used to map snow cover in the various maps are different, resulting in different products. The improved spatial resolution of the MODIS snow maps $(500 \mathrm{~m})$, relative to snow maps derived from other available sensors, e.g. NOAA's Advanced Very High Resolution Radiometer (AVHRR) at $1.1-\mathrm{km}$ resolution, should benefit hydrologists for snow-cover mapping. In this paper, we describe the MODIS snow products, and discuss a case study of early validation efforts from a field and aircraft experiment near Keene, NH, in March 2000, and field measurements in December 2000.

\section{Background}

\subsection{Instrument descriptions}

\subsubsection{MODIS}

MODIS is an imaging spectroradiometer that employs a cross-track scan mirror, collecting optics, and a set of 
individual detector elements to provide imagery of the Earth's surface and clouds in 36 discrete, narrow spectral bands from approximately 0.4 to $14.0 \mu \mathrm{m}$ (Barnes, Pagano, \& Salomonson, 1998). Key land-surface objectives are to study global vegetation and land cover, global land-surface change, vegetation properties, surface albedo, surface temperature, and snow and ice cover on a daily or near-daily basis (Justice et al., 1998). The spatial resolution of the MODIS instrument varies with spectral band, and ranges from $250 \mathrm{~m}$ to $1 \mathrm{~km}$ at nadir.

\subsubsection{MODIS Airborne Simulator (MAS)}

The MAS is a spectroradiometer designed to acquire calibrated radiances. The spectral coverage and radiometric response of an existing multichannel instrument were modified to approximate the narrow spectral bands of the MODIS for measuring scientific parameters of cloud and terrestrial surface targets (King et al., 1996). The MAS, with 50 spectral bands in the wavelength range from 0.55 to 14.2 $\mu \mathrm{m}$, is flown aboard a NASA ER-2 research aircraft at an altitude of about $20 \mathrm{~km}$. Data from MAS channels $1-10$, in the visible, near-infrared and short-wave-infrared parts of the spectrum, are discussed in this paper. The MAS views $43^{\circ}$ on either side of nadir with an Earth swath width of $37.25 \mathrm{~km}$. The $15-\mathrm{cm}$ aperture spatial instantaneous field-ofview is $2.5 \mathrm{mrad}$, or $50-\mathrm{m}$ spatial resolution at nadir from the nominal aircraft height.

\subsubsection{The Landsat Enhanced Thematic Mapper Plus (ETM+)}

The ETM+ was launched on April 15, 1999, on the Landsat-7 satellite (http://www.landsat.gsfc.nasa.gov/project/ satellite.html). The ETM+ has eight discrete bands ranging from 0.45 to $12.5 \mu \mathrm{m}$, and the spatial resolution ranges from $15 \mathrm{~m}$ in the panchromatic band, to $60 \mathrm{~m}$ in the thermal-infrared band. All of the other bands have $30-\mathrm{m}$ resolution. ETM+ data can be accessed as browse products and ordered from the USGS EROS Data Center in Sioux Falls, SD from the following Web address: http://www. edcsns17.cr.usgs.gov/EarthExplorer/. ETM+ data provide a high-resolution view of snow cover that can be compared with the MODIS and operational snow-cover products. However, ETM + data are only acquired once every 16 days and are therefore not frequent enough for mapping changing snow-cover conditions operationally.

\subsection{Snow maps}

\subsubsection{NOAA operational snow maps}

2.2.1.1. National Environmental Satellite, Data and Information Service (NESDIS). The Satellite Analysis Branch of NOAA's NESDIS began to generate Northern Hemisphere Weekly Snow and Ice Cover analysis charts derived from NOAA's GOES and POES visible satellite imager, in November 1966. Maps were manually constructed and the spatial resolution of the charts was 190 km. However, since 1997, a new Interactive Multi-Sensor Snow and Ice Mapping System (IMS) is used by analysts to produce products daily at a spatial resolution of about 25 $\mathrm{km}$, and utilizes a variety of satellite data to produce the maps (Ramsay, 1998). NOAA also produces a daily product, developed by automated techniques, which uses visible, near-infrared and passive-microwave data to map snow cover, and agrees in $85 \%$ of the cases studied, with the IMS product (Romanov, Gutman, \& Csiszar, 2000).

\subsubsection{The National Operational Hydrologic Remote} Sensing Center (NOHRSC) maps. NOHRSC snow-cover maps, generated by National Weather Service NOHRSC hydrologists, are distributed electronically in near real time, to local, state and federal users during the snow season (Carroll, 1995). The NOHRSC 1-km maps are generated primarily from the NOAA polar-orbiting satellites and the Geostationary Orbiting Environmental Satellite (GOES) satellites to develop daily digital maps depicting the areal extent of snow cover for the coterminous United States, and Alaska, and portions of southern Canada.

\section{Discussion and conclusion}

A sequence of MODIS snow-cover products is presented. The swath products are mapped to the integerized sinusoidal grid to create the daily tile product. Eight days of the daily tile products are used to produce the 8-day composite tile product. These products are at 500-m resolution. The CMG product is produced at $0.05^{\circ}(\sim 5.6-\mathrm{km})$ resolution and consists of daily and 8-day composite products. Examples of the products are shown, focusing on the site of a field and aircraft experiment from March 6, 2000, and fieldwork on December 23, 2000. The MODIS snow map shows patchy snow cover on March 6th, as confirmed by the field measurements. However, nearly complete snow cover is mapped near Keene on December 23rd, which is an overestimation of snow cover as compared to the ETM+-derived map for the same day, as confirmed by field measurements but is likely due to the greater resolution of the MODIS image relative to the $\mathrm{ETM}^{+}$image.

Other work shows that the MODIS snow-cover maps compare favorably with current operational maps (Hall et al., in press), and perform better than do passive microwavederived snow-cover maps during the daytime and in the fall months in the Northern Hemisphere when the snow is still wet.

Future enhancements to the MODIS snow maps include daily snow albedo (Klein et al., 2000), which should be available in the fall of 2002, and fractional snow cover at 500-m spatial resolution. Future re-processing will allow all of the MODIS snow maps to be processed in a consistent manner. 